\title{
Morphine Administered in the Substantia Gelatinosa of the Spinal Trigeminal Nucleus Caudalis Inhibits Nociceptive Activities in the Spinal Trigeminal Nucleus Oralis
}

\author{
Radhouane Dallel, Christian Dualé, and Jean-Louis Molat \\ Laboratoire de Physiologie Oro-Faciale, Faculté de Chirurgie Dentaire, 63000 Clermont-Ferrand, France
}

\begin{abstract}
The present study investigates the effects of morphine microinjection into the spinal trigeminal nucleus caudalis (Sp5C) or the spinal trigeminal nucleus oralis (Sp5O) on C-fiber-evoked activities of Sp5O convergent neurons, after supramaximal percutaneous electrical stimulation in halothane-anesthetized rats.

When it was microinjected into the Sp5O, morphine $(2.5 \mu \mathrm{g}$ in $0.25 \mu \mathrm{l})$ never depressed the C-fiber-evoked responses of Sp50 convergent neurons ( $n=13)$, whereas these neurons were responsive to the inhibitory effects of systemic morphine (6 mg/kg, i.v.) in a naloxone-reversible manner. On the contrary, morphine microinjected into the $\mathrm{Sp} 5 \mathrm{C}$ produced a naloxonereversible inhibition of the C-fiber-evoked responses of Sp5O neurons $(n=14)$. The magnitude and the time course of this effect varied according to the location of the injection sites. After microinjection into the superficial laminae $(n=7)$, a strong depressive effect of morphine ( $\pm \pm 5 \%$ of control) on the C-fiber-evoked responses was apparent as soon as 5 min after
\end{abstract}

In recent years, we have accumulated electrophysiological data showing that the spinal trigeminal nucleus oralis (Sp5O) contributes to the processing of nociceptive information coming from the orofacial region. We have demonstrated the presence, in this subnucleus, of two categories of nociceptive neurons: convergent or wide dynamic range neurons and nociceptive specific neurons, which have their receptive fields located mainly within or around the oral cavity (Dallel et al., 1990). The Sp5O convergent neurons respond to mechanical, thermal, chemical, or electrical cutaneous (or mucosal) noxious stimuli (Dallel et al., 1990, 1996a; Raboisson et al., 1991, 1995) and encode the intensities of electrical and mechanical stimulation. The susceptibility of $\mathrm{Sp} 5 \mathrm{O}$ neurons to sensitivity changes has also been observed. The phenomenon of wind-up, which consists of a progressive increase in the C-fiberevoked response after repeated percutaneous electrical stimulation, is observed for most $\mathrm{Sp5O}$ convergent neurons (Dallel et al., 1990). Wind-up has been shown to be mediated by activation of NMDA receptors and is suggested to be the basis for central sensitization (for review, see Dickenson, 1995). Stimulation of small-diameter afferents supplying deep tissues also increased the excitability of $\mathrm{Sp5O}$ neurons responding to cutaneous afferent

\footnotetext{
Received Oct. 31, 1997; revised Jan. 29, 1998; accepted Feb. 26, 1998.

This work was supported by L'Institut UPSA de la douleur. We are grateful to Dr. P. Raboisson for thoughtful comments and suggestions and M. Alden for English language editing. We also thank A. M. Gaydier for secretarial help and M. Chalus for histological assistance.

Correspondence should be addressed to R. Dallel, Laboratoire de Physiologie Oro-Faciale, Faculté de Chirurgie Dentaire, 11 Boulevard Charles de Gaulle, 63000 Clermont-Ferrand, France.

Copyright (C) 1998 Society for Neuroscience $\quad 0270-6474 / 98 / 183529-08 \$ 05.00 / 0$
}

the injection and could always be reversed by naloxone, administered either intravenously $(0.4 \mathrm{mg} / \mathrm{kg})$ or locally $(2.5 \mu \mathrm{g}$ in $0.6 \mu \mathrm{l})$ at the same site as morphine. After microinjection into deeper laminae $(\mathrm{V}-\mathrm{VI})$, a significant depressive effect $(34 \pm 5 \%$ of control) of morphine could be detected only 20 min after the injection and was reversed only by intravenous administration of naloxone.

These results suggest that morphine exerts its antinociceptive action on Sp5O convergent neurons by blocking the $\mathrm{C}$-fiber inputs that relay in the Sp5C substantia gelatinosa. The mechanisms that underlie the activation of Sp5O convergent neurons by $\mathrm{C}$-fibers and the inhibition of $\mathrm{C}$-fiber-evoked responses of Sp50 convergent neurons by morphine microinjected into the $\mathrm{Sp} 5 \mathrm{C}$ are discussed.

Key words: nociception; trigeminal; substantia gelatinosa; convergent neuron; C-fiber; rat inputs (Hu et al., 1992). This was reflected by an expansion of the cutaneous mechanoreceptive field, by an increase in spontaneous activity, or in responsivity to electrical stimulation of cutaneous afferent inputs to the neurons. Such facilitation may contribute to the tenderness, spread, and referral of pain after injury of deep tissues (Woolf and Wall, 1986; Cook et al., 1987). The transmission of nociceptive signals in the $\mathrm{Sp} 5 \mathrm{O}$ can be modulated by powerful controls. For example, the evoked activity of Sp5O convergent neurons could be suppressed by the application of noxious stimuli to any body areas distant from their excitatory receptive fields (Dallel et al., 1990; Raboisson et al., 1995). This phenomenon, termed diffuse noxious inhibitory controls, is considered to be mediated by supraspinal mechanisms (for review, see Villanueva and Le Bars, 1995).

Recently, we have demonstrated that the C-fiber-evoked responses of Sp5O convergent neurons are depressed in a dosedependent and naloxone reversible manner by systemic morphine (Dallel et al., 1996a). Because of the systemic administration of morphine, it was not possible to determine where morphine exerts its action, but three hypotheses (Dallel et al., 1996a) have been proposed. First, morphine may reinforce descending inhibitory controls that originate from the brainstem and act on the Sp5O neurons. Second, morphine could possibly act directly at the level of the Sp5O. Finally, morphine may depress Sp5O neuron activities via an action through the spinal trigeminal nucleus caudalis (Sp5C).

This experiment was undertaken to examine the two last hypotheses by studying the effects of microinjected morphine into the $\mathrm{Sp} 5 \mathrm{C}$ or $\mathrm{Sp} 5 \mathrm{O}$ on $\mathrm{C}$-fiber-evoked activities of $\mathrm{Sp} 5 \mathrm{O}$ conver- 
gent neurons after supramaximal percutaneous electrical stimulation.

Parts of this paper have been presented previously in abstract form (Dallel et al., 1996b).

\section{MATERIALS AND METHODS}

Animal preparation. Experiments were performed on male Sprague Dawley rats weighing 220-300 gm, in accordance with the guidelines of the International Association for the Study of Pain and the National Institutes of Health Guide for the Care and Use of Laboratory Animals. For surgery, the animals were anesthetized with $2 \%$ halothane in a nitrous oxide/oxygen mixture (2:1). After intraperitoneal injection of $100 \mu \mathrm{g}$ atropine sulfate, a tracheal cannula was inserted, the jugular vein was cannulated, and the animals were paralyzed by an intravenous perfusion of pancuronium bromide $(0.5 \mathrm{mg} / \mathrm{h})$ and artificially ventilated with a volume-controlled pump (54-55 strokes/min). The levels of halothane, $\mathrm{O}_{2}, \mathrm{~N}_{2} \mathrm{O}$, and the end-tidal $\mathrm{CO}_{2}(3.5-4.5 \%)$ were monitored by an anesthetic gas monitor (Artema MM 200, Sundbyberg, Sweden) during the entire experimental period. These parameters were measured by infrared absorption, digitally displayed, and under the control of alarms. Adequate anesthesia was confirmed periodically by the lack of spontaneous movements or arousal responses evoked by the application of noxious stimuli, and the vascularization of the cutaneous tissues was periodically checked by observing the color of the paw extremities and the rapidity by which they regained normal color after the application of pressure to the paw. The heart rate was also monitored continuously, and core temperature was maintained at $38 \pm 0.5^{\circ} \mathrm{C}$ with a homeothermic blanket system.

The animals were placed in a stereotaxic frame with the head fixed in a ventroflexed position (incisor bar dropped $5 \mathrm{~mm}$ under the standard position) by means of an adapted metallic bar. A craniotomy was performed on the right side at the level of the occipitoparietalis suture, and the dura mater was removed. Wound margins were infiltrated with local anesthetic. After surgery, the level of halothane was reduced to $0.5 \%$ and maintained at this level during the recording period. This percentage allowed a level of anesthesia that was adequate for ethical purposes but did not excessively depress neuronal responses to noxious stimuli (Villanueva et al., 1988).

Microinjections. The drugs were delivered by three-barrel glass micropipettes (3GC120F-15; Clark Electromedical Instruments, Pangbourne, UK) fixed on the micromanipulator and connected to three Hamilton syringes $(1 \mu \mathrm{l})$ by means of polyethylene tubing. The micropipette was broken back maximally to a diameter of $70-100 \mu \mathrm{m}$. The micropipettes and tubing were filled with morphine hydrochloride, naloxone, or saline with pontamine sky blue, respectively (for location of the injection site). Injections of drugs were performed with a manual injector over a period of $2 \mathrm{~min}$ and monitored by observing the movement of an air bubble in the tubing. The slow rate of injection was chosen to minimize the chance of tissue damage. The micropipettes remained in place throughout the experimental session.

For injection into the $\mathrm{Sp} 5 \mathrm{C}$ the caudal medulla was exposed by removing the overlying musculature, atlanto-occipital membrane, and dura mater. The micropipette was positioned stereotaxically above the targeted brainstem site $1 \mathrm{hr}$ before the injection. The micropipette tip was lowered $1.5 \mathrm{~mm}$ below the pial surface and slowly elevated $0.5 \mathrm{~mm}$. The medulla was then covered by $2 \%$ Ringer's solution-agar gel. The coordinates used for microinjection sites were $5.3 \mathrm{~mm}$ posterior to the interaural plane (approximately obex) and $1.0-2.8 \mathrm{~mm}$ lateral to the midline (Paxinos and Watson, 1986). The micropipette was placed at this level because the mandibular and maxillary trigeminal divisions, which are the main afferent inputs to the $\mathrm{Sp} 5 \mathrm{O}$, are heavily represented in the rostral part of the Sp5C (Jacquin et al., 1983; Takemura et al., 1991). In addition, anatomical investigations have demonstrated that this part of the Sp5C is at the origin of ascending intranuclear trigeminal pathways to the Sp5O (Ikeda et al., 1984; Nasution and Shigenaga, 1987).

To attain the $\mathrm{Sp} 5 \mathrm{O}$, the micropipette was introduced posterior to the recording microelectrode at an angle of $15^{\circ}$ toward the anterior plane, so that the tip of the micropipette was $\sim 0.5 \mathrm{~mm}$ distant from the recording microelectrode. The choice of this distance was based on the autoradiographic data of Dickenson and Le Bars (1987) and Burkey et al. (1996), who have observed that $0.2 \mu \mathrm{l}$ of morphine diffuses largely in a $1.5-\mathrm{mm}-$ diameter sphere of brain tissue.

Recordings. Unitary extracellular recordings were made with glass micropipettes $(8-10 \mathrm{M} \Omega)$ filled with a mixture of $5 \% \mathrm{NaCl}$ and pon- tamine sky blue. The brainstem was explored 2.4-3.0 $\mathrm{mm}$ lateral to the midline and between the frontal planes P. 1.1 and P. 2.6 (Paxinos and Watson, 1986). Single unit activities were amplified and displayed on oscilloscopes and were also led into a window discriminator connected to a CED 1401plus interface (Cambridge Electronic Design) and a PC computer (Spike 2.01 software), to allow sampling and analysis of the spontaneous and evoked neuronal activity.

Neurons were classified as convergent on the basis of their responses to both mechanical and percutaneous electrical stimulation applied to their receptive field. All neurons responded to both innocuous and noxious mechanical stimuli and showed electrically evoked responses corresponding to both $\mathrm{A}$ - and $\mathrm{C}$-fiber inputs (see below).

Innocuous mechanical stimulation of the skin, mucosa, and teeth included air puffs, brushing with a soft brush, gentle stroking, and light pressure with a blunt probe. Noxious mechanical stimuli consisted of heavy pressure, pinprick, and pinching with fine forceps, which evoked a painful sensation when applied to the experimenters' skin. Once a neuron had been identified, the extent of its receptive field was determined and mapped onto scale drawings of the rat's face, and its location was defined in terms of its involvement in intraoral, perioral, or more peripheral regions of the face (Dallel et al., 1990).

Electrical square-wave stimuli $(0.66 \mathrm{~Hz}, 2 \mathrm{msec}$ duration) were applied through a pair of stainless steel stimulating electrodes inserted subcutaneously into the center of the previously delineated receptive field. The threshold for obtaining a $\mathrm{C}$-fiber response was determined: increasing the current to a suprathreshold value induced reproducible responses. Poststimulus histograms were analyzed to distinguish responses caused by $\mathrm{A}$ - and $\mathrm{C}$-fiber inputs, according to their latencies and by using the classification of Gasser and Erlanger (1927) and Burgess and Perl (1973). The latency value of the responses was used to determine the conduction velocity of afferent inputs after making allowance for the conduction distance $(\sim 50 \mathrm{~mm})$ and $1 \mathrm{msec}$ for the central synaptic delay, the delay in activation of the peripheral axons, and the narrowing of afferents in the trigeminal spinal tract. Neurons responding with a discharge burst at a latency $>30$ msec were considered to be excited by C-fibers (Hu, 1990; Raboisson et al., 1995). In addition, we have shown recently (our unpublished data) that these long latency responses were selectively blocked by the intracutaneous injection of capsaicin $(0.1 \%)$, which is known to preferentially block selectively the unmyelinated C-fibers (Holzer, 1991).

Experimental design. The experimental procedure consisted of sequences of 50 electrical shocks applied repeatedly $(0.66 \mathrm{~Hz})$ to the excitatory receptive field at three times the threshold for $\mathrm{C}$-fiber activation. This type of stimulation gave an intense and stable response. Sequences were repeated at $5 \mathrm{~min}$ intervals.

When two successive control sequences with a variation of $<10 \%$ in the magnitude of $\mathrm{C}$-fiber-evoked responses had been recorded, a single dose of morphine hydrochloride $(2.5 \mu \mathrm{g}$ in $0.25 \mu \mathrm{l})$ was microinjected into the $\mathrm{Sp} 5 \mathrm{O}$ or $\mathrm{Sp} 5 \mathrm{C}$. This dose was chosen because it produces analgesia in the awake rat when injected at different levels of the CNS (Dickenson et al., 1979; Rosenfeld et al., 1983; Yaksh et al., 1988). Knowing that in behavioral and electrophysiological studies (Dickenson et al., 1979; Le Bars et al., 1980; Gebhart and Jones, 1988; Yaksh et al., 1988; Dallel et al., 1996a) it has been observed that the maximal analgesic effect of morphine occurs within $10 \mathrm{~min}$ after injection, we performed tests at 5, 10, and $20 \mathrm{~min}$ after injection. If the morphine effect did not attenuate the unit response to $<75 \%$ of the control response, a systemic injection of morphine $(6 \mathrm{mg} / \mathrm{kg}$, i.v.) was made to check the susceptibility of the unit to morphine.

The specificity of the observed effects was tested by naloxone administered either at the same sites $(2.5 \mu \mathrm{g}$ in $0.6 \mu \mathrm{l})$ as morphine or given intravenously $(0.4 \mathrm{mg} / \mathrm{kg})$.

In each experiment, the mean of the two controls was taken as the reference value for subsequent calculation of the effects of morphine administration on the evoked responses. Inhibition was expressed as the percentage decrease in the number of spikes with $\mathrm{C}$-fiber latencies, with reference to the control.

In each animal, one Sp5O cell was tested, and only cells showing no alteration in spike amplitude or waveform during the complete experimental procedure were considered.

Statistical analysis. The data were analyzed by ANOVA followed by Newman-Keuls test. The level of significance was set at $p<0.05$. The results are expressed as mean \pm SEM.

Histological analysis. Recording and microinjection sites were visualized by injection of pontamine sky blue solution at the end of the experiment. After the animal was killed by injection of a lethal dose of 


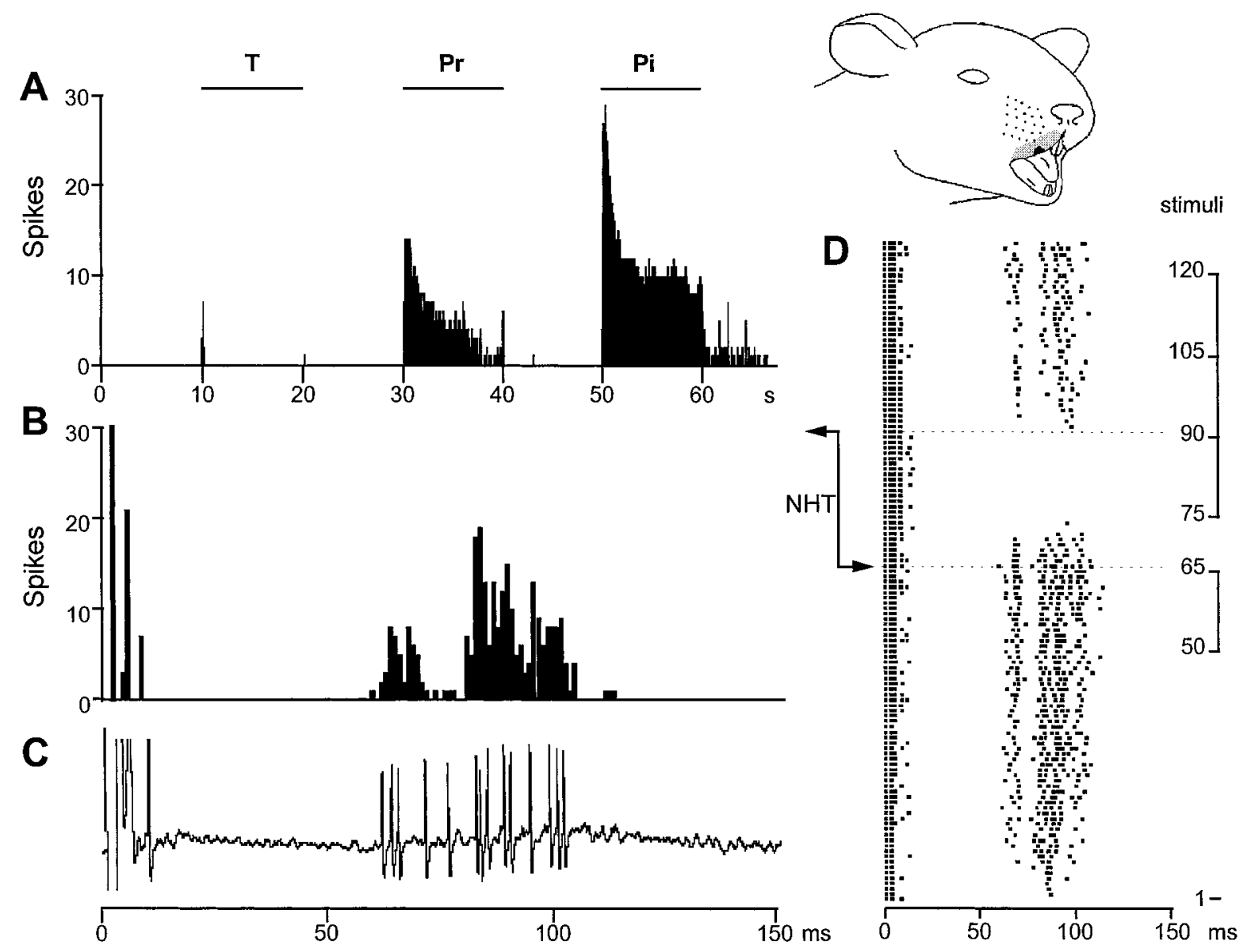

Figure 1. Individual example of electrophysiological characteristics of a spinal trigeminal nucleus oralis convergent neuron. $A$, Responses to mechanical stimulation ( $T$, touch; $P r$, pressure; $P i$, pinch) applied to its receptive field (shown in gray). $B$, Responses to repetitive (50 trials) percutaneous electrical stimulation $(0.66 \mathrm{~Hz}, 2 \mathrm{msec}$ duration) of its receptive field at three times the threshold for $\mathrm{C}$-fibers activation. $C$, Oscilloscope single sweep was recorded after the 15 th stimulation and shows the A- and C-fiber-evoked responses. $D$, Inhibitory effect induced by the immersion of the tail in hot water $\left(52^{\circ} \mathrm{C}\right)$ after the response of one Sp5O convergent neuron to percutaneous suprathreshold $(3 \times$ threshold $)$ electrical stimulation of its receptive field. The dots display an analysis in which the successive responses shown from bottom (1st stimulus) to top (120th stimulus), as indicated on the right, illustrates one of the complete sequences of stimuli. Noxious heat was applied to the tail (NHT) during 25 trials (65th-90th). The first 50 responses were used for the study of unconditioned responses, showing the progressive building up of the C-fiber-evoked response (wind-up) from the 1st to the 14th stimulation, whereas the following were used for the study of diffuse noxious inhibitory controls. In this latter case, the 50th-65th responses constituted the control for the subsequent inhibitory effects and aftereffects (90th-105th). The last responses (105th-120th) allowed visualization of recovery. Note the strong depressive effects during the period (75th-90th) of heterotopic stimulation and in the following seconds (90th-105th).

pentobarbital, the brain was removed and fixed in a $10 \%$ formalin solution for 1 week. The tissue was frozen, cut into serial $100-\mu$ m-thick sections, and stained with neutral red. Recording and microinjection sites were determined by microscopic examination and then plotted on camera lucida drawings of serial sections.

\section{RESULTS}

\section{General properties of convergent neurons}

A total of 30 convergent neurons were recorded within the Sp5O. They were located throughout the dorsoventral extent of the nucleus, between the frontal planes P 1.1-2.2 (Paxinos and Watson, 1986). Most of neurons were not spontaneously active. All had an ipsilateral receptive field that included the intraoral or perioral region. They were sensitive to both innocuous and noxious mechanical stimuli and responded by increasing their firing rate as the intensity of the stimuli increased into the noxious range (Fig. $1 A)$.

When we applied $2 \mathrm{msec}$ percutaneous electrical stimuli to the center of the excitatory receptive field of the neurons, responses attributable to peripheral activation of A- and C-fibers could be observed (Fig. 1B,C). The responses attributable to C-fibers were obtained at a mean threshold of $8.1 \pm 0.7 \mathrm{~mA}$ and with a mean latency of $73.2 \pm 3.0 \mathrm{msec}$, which corresponds to peripheral fibers with conduction velocities of $\sim 0.7 \mathrm{~m} / \mathrm{sec}$. In most cases the response attributable to $\mathrm{C}$-fibers exhibited a wind-up phenomenon during repetitive $(0.66 \mathrm{~Hz})$ suprathreshold electrical stimulation (Fig. $1 D$ ). The evoked activity of $\mathrm{Sp} 5 \mathrm{O}$ convergent neurons could be suppressed by heat noxious stimulation applied to the tail $\left(52^{\circ} \mathrm{C}\right)$, and this was followed by long-lasting poststimulus effects (Fig. 1D).

\section{Effects of morphine microinjected on C-fiber-evoked responses of Sp50 convergent neurons}

The neurons that were tested fell into two groups: 16 cells that were not influenced by microinjected morphine and 14 that were inhibited by morphine.

\section{Neurons not influenced by morphine}

The injection sites corresponding to these units were located in the $\operatorname{Sp5O}(n=13)$ or in the medullary reticular nucleus at the 


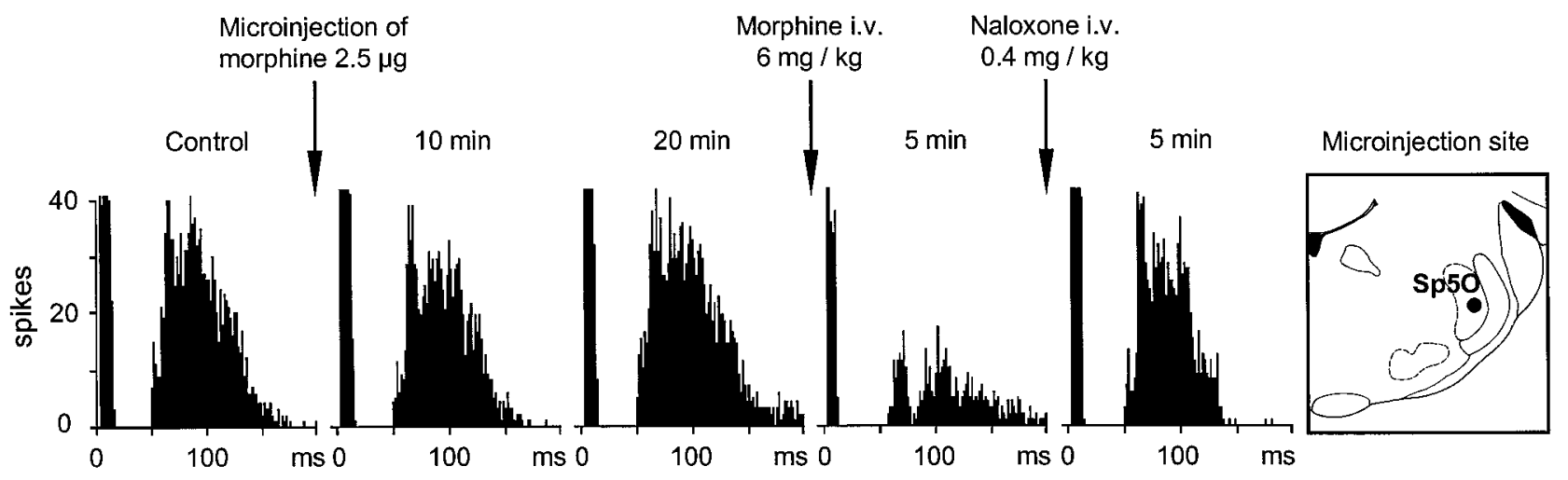

Figure 2. Individual example of the lack of effect of morphine microinjected ( $2.5 \mu \mathrm{g}$ in $0.25 \mu \mathrm{l})$ into the Sp5O, on the C-fiber-evoked responses of Sp5O convergent neurons. Poststimulus histograms (50 trials) were made before (controls) and after morphine administration as well as after naloxone administration (postinjection times are indicated at the top). The systemic administration of morphine $(6 \mathrm{mg} / \mathrm{kg}) \mathrm{strongly}$ depressed the neuronal response in a naloxone-reversible manner.

level of the obex $(n=3)$. A typical example is given in Figure 2 in the form of poststimulus histograms showing no alteration of the response of the neuron after morphine microinjection into the $\mathrm{Sp5O}$. However, these neurons were responsive to the inhibitory effects of systemic morphine, because intravenous administration of $6 \mathrm{mg} / \mathrm{kg}$, a dose close to the $\mathrm{ED}_{50}$ for $\mathrm{C}$-fiber inhibition (Dallel et al., 1996a), profoundly depressed the C-fiber-evoked response of the neuron. This effect was reversed by naloxone $(0.4 \mathrm{mg} / \mathrm{kg}$, i.v.). Compared with the administration in the Sp5C (Figs. 3, 4), the mean response of the neurons was not significantly altered by morphine microinjection into the Sp5O. The responses were $96 \pm$ $3 \%, 87 \pm 4 \%$, and $104 \pm 6 \%$ of the initial value, 5,10 , and $20 \mathrm{~min}$, respectively, after microinjection of morphine. In contrast, intravenous administration of $6 \mathrm{mg} / \mathrm{kg}$ of morphine reduced the $\mathrm{C}$-evoked response of the neurons to $37 \pm 5 \%$ of the initial value $5 \mathrm{~min}$ after the injection, a reduction that was reversed (97 \pm $17 \%)$ by systemic naloxone $(0.4 \mathrm{mg} / \mathrm{kg}$, i.v. $)$.

It must be noted that a slight decrease of response $(90 \pm 3 \%)$ was observed after 20 min when morphine was injected into the medullary reticular nucleus at the level of the obex (Fig. 4).

\section{Neurons inhibited by morphine}

Morphine microinjected into the $\mathrm{Sp} 5 \mathrm{C}$ produced a naloxonereversible depression of the $\mathrm{C}$-fiber-evoked responses of $14 \mathrm{Sp} 5 \mathrm{O}$ convergent neurons. The magnitude and the time course of the effects varied according to the location of the injection sites (Figs. 3, 4).

After microinjection in the superficial laminae of the Sp5C $(n=7)$, a strong depressive effect of morphine $(7 \pm 5 \%$ of control) on C-fiber-evoked responses was apparent as soon as 5 min after the injection. This is illustrated by an individual example in Figure $3 A$. Neuron responses were totally inhibited $5 \mathrm{~min}$ after the injection in five of seven cases and $10 \mathrm{~min}$ after for the two remaining cases. These effects were always completely reversed by naloxone administered either intravenously $(0.4 \mathrm{mg} / \mathrm{kg})$ or locally $(2.5 \mu \mathrm{g}$ in $0.6 \mu \mathrm{l})$ at the same site as morphine (Fig. $3 A$ ). A facilitatory effect was frequently observed after microinjection of naloxone (three of four cases).

After microinjection into laminae III-IV $(n=4)$, the responses were totally inhibited $10 \min (n=2)$ or $20 \min (n=2)$ after the injection. These effects were partially reversed $(61 \pm 23 \%)$ by naloxone microinjected $(2.5 \mu \mathrm{g}$ in $0.6 \mu \mathrm{l})$ at the same site as morphine, but they were completely reversed $(123 \pm 29 \%)$ by intravenous administration of naloxone $(0.4 \mathrm{mg} / \mathrm{kg})$.
After microinjection into the deeper laminae (V-VI), the depressive effect of morphine on $\mathrm{C}$-fiber-evoked responses was significant only $20 \mathrm{~min}$ after the injection. This is illustrated by an individual example in Figure $3 B$ that also shows that the depression was completely reversed only by naloxone administered intravenously. The cumulative results obtained from three neurons are presented in Figure 4. The responses were reduced to $91 \pm 17 \%, 71 \pm 4 \%$, and $34 \pm 5 \%$ of the initial value 5,10 , and $20 \mathrm{~min}$, respectively, after microinjection of morphine. These effects were reversed only by intravenous administration of naloxone $(0.4 \mathrm{mg} / \mathrm{kg})$.

\section{DISCUSSION}

This is the first electrophysiological study that investigates the effects of morphine microinjections into the Sp5C or the Sp5O on $\mathrm{C}$-fiber-evoked activities of $\mathrm{Sp} 5 \mathrm{O}$ convergent neurons. The results indicate that only morphine microinjection within the $\mathrm{Sp} 5 \mathrm{C}$ inhibits $\mathrm{C}$-fiber-evoked responses of $\mathrm{Sp} 5 \mathrm{O}$ convergent neurons.

The response characteristics of the convergent neurons recorded in this experiment are in general agreement with data from former studies of the Sp5O (Dallel et al., 1990, 1996a; Raboisson et al., 1995) and are comparable to those of lumbar and Sp5C convergent neurons (Besson and Chaouch, 1987; Willis and Coggeshall, 1991). The neurons tested had a mechanoreceptive field involving oral or perioral regions and were sensitive to both innocuous and noxious mechanical stimuli. They responded to the activation of peripheral $\mathrm{A}$ - and $\mathrm{C}$-fibers, and their $\mathrm{C}$-fiber components frequently exhibited the wind-up phenomenon during repetitive suprathreshold electrical stimulation. The evoked activity of Sp5O convergent neurons could be suppressed by noxious stimulation applied to any body area.

The major finding of the present study was that morphine microinjected into the Sp5C depressed the C-fiber-evoked activities of Sp5O convergent neurons. This effect was powerful and rapid, because it was apparent as soon as 5 min after the injection. The time course of the effect of the microinjected morphine was consistent with a local site action for morphine and similar to what has been observed in behavioral and electrophysiological studies (Oliveras et al., 1986; Gebhart and Jones, 1988; Yaksh et al., 1988). Morphine effects are more likely a result of a direct effect on Sp5C neuronal activity than of a diffusion to other loci outside the $\mathrm{Sp5C}$. Indeed, we used a relatively small microinjection system (i.e., diameter $<100 \mu \mathrm{m}$ ), compared with the dimensions of the $\mathrm{Sp} 5 \mathrm{C}$, and doses in the lower end of the range of those 

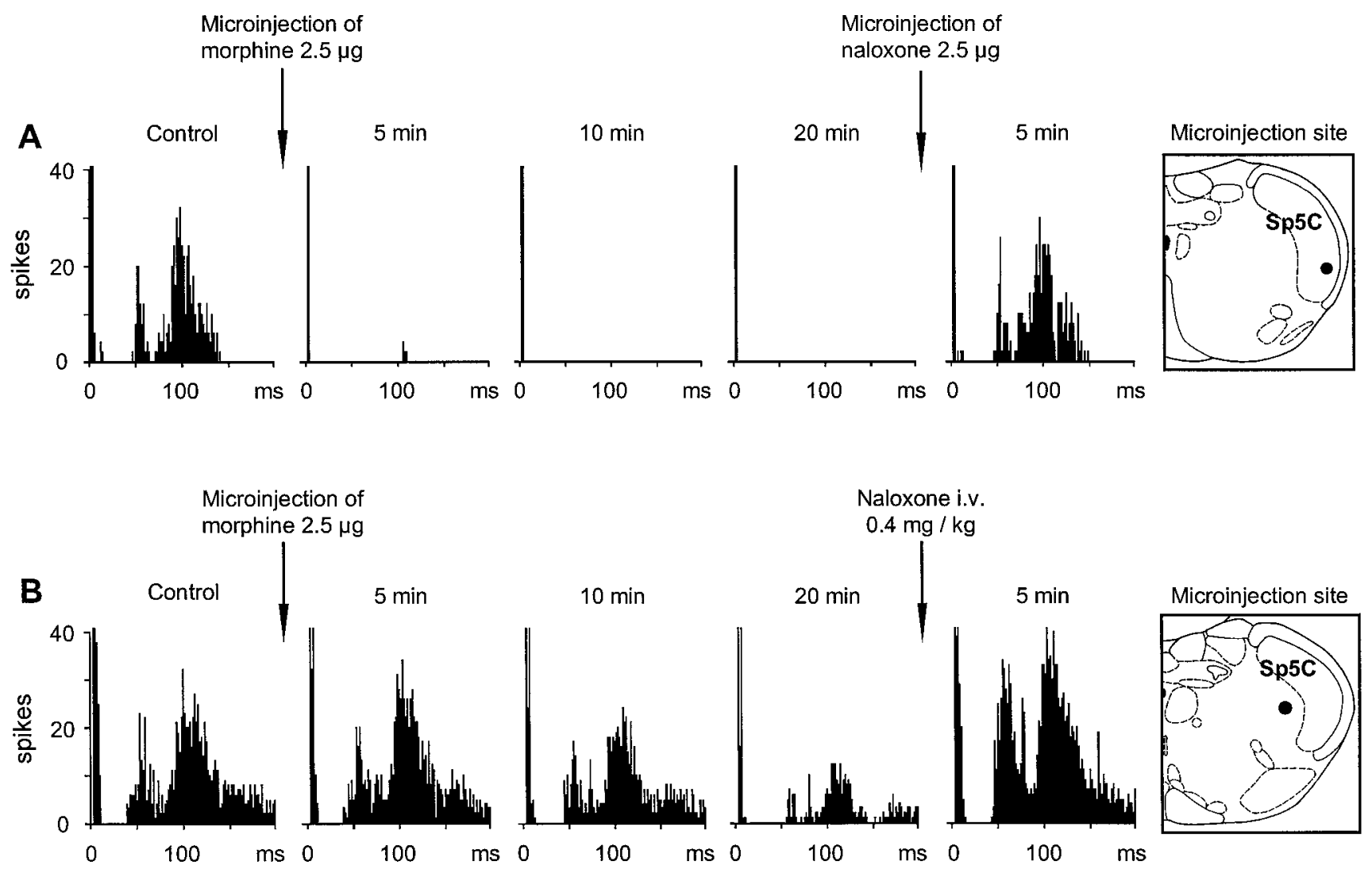

Figure 3. Examples of naloxone-reversible inhibition of the $\mathrm{C}$-fiber-evoked responses of $\mathrm{Sp} 5 \mathrm{O}$ convergent neurons by morphine microinjected into the superficial laminae $(A)$ or into the deep laminae $(B)$ of the Sp5C. Microinjection of morphine in the superficial laminae (I-II) produced a rapid and strong inhibition of $\mathrm{C}$-fiber-evoked responses that was reversed by microinjected naloxone $(2.5 \mu \mathrm{g}$ in $0.6 \mu \mathrm{l})$ into the Sp5C. Microinjection into the deep laminae (V-VI) induced a significant depressive effect only $20 \mathrm{~min}$ after the injection. This effect is completely reversed only by systemic naloxone (0.4 mg/kg).

used previously (Yaksh et al., 1988). The depression of the Sp5O convergent neurons was reversed by naloxone either applied locally by microinjection or given systemically in doses appropriate for reversal of the antinociception induced by systemic morphine administration (Le Bars et al., 1980; Oliveras et al., 1986; Gebhart and Jones, 1988; Thomas et al., 1992; Dallel et al., 1996a). Thus, the rapidity of the effects of morphine, its reversal by naloxone applied locally in the Sp5C, and the observation that morphine administered far (medial or rostral) from the Sp5C did not alter the responses of the $\mathrm{Sp} 5 \mathrm{O}$ convergent neurons provides strong functional evidence that morphine remained within the Sp5C.

On the contrary, morphine microinjected into the Sp5O never produced any depression of the $\mathrm{C}$-fiber-evoked response of $\mathrm{Sp} 5 \mathrm{O}$ convergent neurons. The lack of inhibitory effect was clear for the 13 cells recorded and was expected because the $\mathrm{Sp} 5 \mathrm{O}$ has been shown to be devoid of opiate receptors (Atweh and Kuhar, 1977) and enkephalinergics neurons (Hökfelt et al., 1977; Sar et al., 1978; Finley et al., 1981; Sumal et al., 1982; Khachaturian et al., 1983; Murakami et al., 1987). In accordance with this, Andersen et al. (1977) have demonstrated that morphine administered microelectrophoretically near the somata of $\mathrm{Sp5O}$ neurons does not generally affect their spontaneous firing.

Several other lines of evidence support our results. (1) Autoradiographic binding and immunohistochemical studies have demonstrated a high density of opiate receptors in the Sp5C (Atweh and Kuhar, 1977; Arvidsson et al., 1995; Ding et al., 1996). (2) Microinjected morphine into the Sp5C alters the de- tection of noxious heat in behaving monkey (Oliveras et al., 1986), depresses the nociceptive behavior induced by a subcutaneous injection of formalin in the upper lip (Dualé et al., 1996), or significantly increases the latency of a defensive face-rub reaction in response to noxious facial heat (Rosenfeld et al., 1983). (3) Iontophoretically applied morphine produces a naloxone-reversible inhibition of $\mathrm{Sp} 5 \mathrm{C}$ nociceptive neurons (Andersen et al., 1977) and reduces glutamate-evoked (Grudt and Williams, 1994) or NMDA-evoked (Zhang et al., 1996) responses of Sp5C nociceptive neurons. (4) Finally, opioid agonists administered locally or systemically have been shown to inhibit the release of immunoreactive substance P in the Sp5C (Jessell and Iversen, 1977; Yonehara et al., 1986, 1990; Suarez-Roca and Maixner, 1992).

\section{Site of action}

Although the present experiments do not indicate specifically where morphine exerts its action within the $\mathrm{Sp} 5 \mathrm{C}$, it seems reasonable to suggest that it is in the substantia gelatinosa. We observed, indeed, that morphine microinjected into the superficial laminae of the Sp5C induced a stronger and more rapid effect than microinjection into the deeper laminae. In addition, autoradiographic binding and immunohistochemical studies have revealed that the substantia gelatinosa of the $\mathrm{Sp} 5 \mathrm{C}$ is the region in the trigeminal sensory complex that contains the highest density of opiate receptors and enkephalinergic neurons (Atweh and Kuhar, 1977; Arvidsson et al., 1995; Ding et al., 1996). Further- 
Figure 4. Pooled results $(n=14)$ showing the time course of the effects of morphine microinjected into laminae I-II $(n=7)$, laminae III-IV $(n=4)$, or laminae V-VI $(n=3)$ of the Sp5C on the $\mathrm{C}$-fiber-evoked responses of $\mathrm{Sp} 5 \mathrm{O}$ convergent neurons. Note that the magnitude and the time course of this effect varied according to the location of the injection sites. After microinjection into the superficial laminae, a strong depressive effect of morphine on $\mathrm{C}$-fiberevoked responses was apparent after 5 min, whereas after microinjection into deeper laminae (V-VI), a significant depressive effect of morphine could be detected only 20 min after the injection. The nomenclature of nuclei is based on Paxinos and Watson (1986): $G r$, gracile nucleus; $\mathrm{Cu}$, cuneate nucleus; $L R t$, lateral reticular nucleus; $M d V$, medullary reticularis nucleus; 12, hypoglossal nucleus.

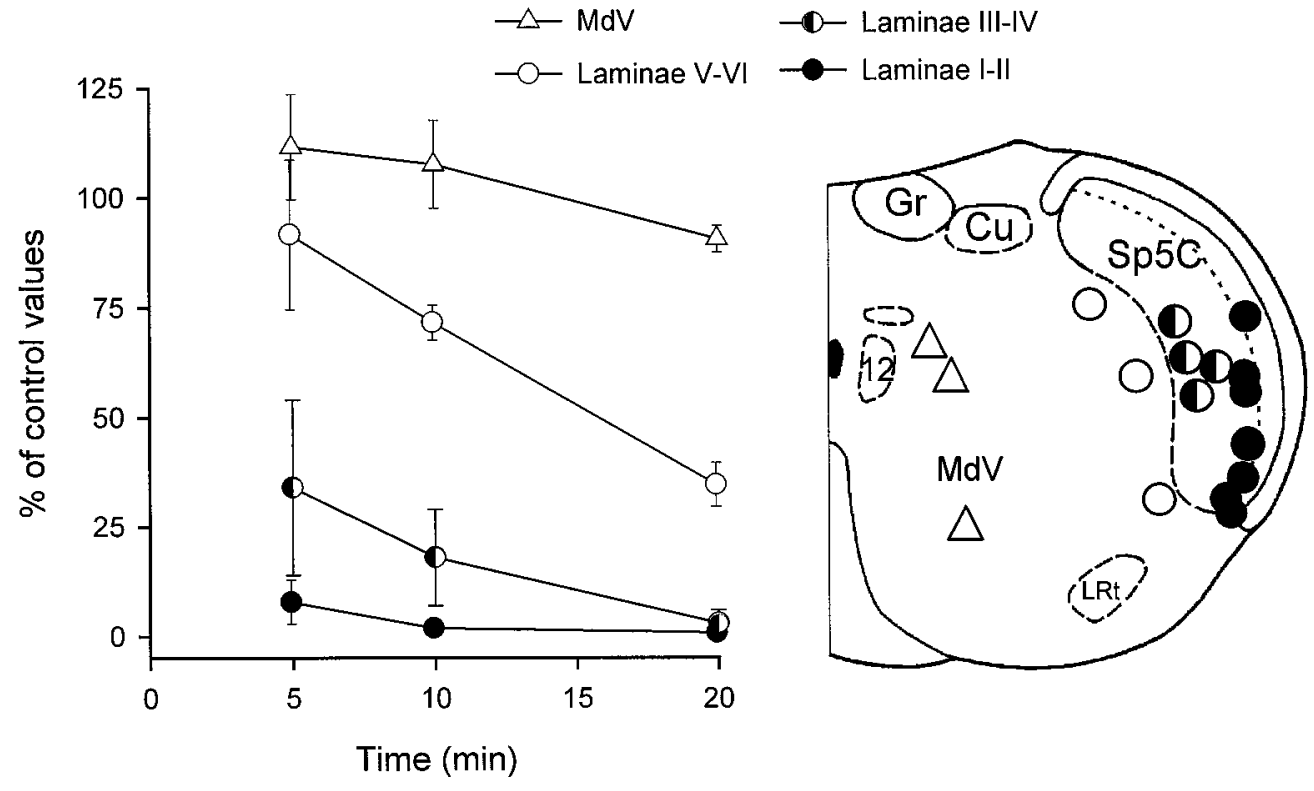

more, in the spinal dorsal horn, iontophoretic administration of opioid agonists into substantia gelatinosa was shown to inhibit the response of deeper laminae convergent neurons to peripheral noxious stimulation in vivo (Duggan et al., 1977; Sastry and Goh, 1983) and to reduce the glutamate-mediated EPSPs of Sp5C substantia gelatinosa neurons in vitro (Grudt and Williams, 1994). Finally, naloxone administered in the substantia gelatinosa fully reversed the effects of systemic morphine on dorsal horn neurons (Johnson and Duggan, 1981).

\section{Mechanism of action}

There is evidence suggesting that the $\mathrm{Sp5O}$ receives $\mathrm{C}$-inputs indirectly via the Sp5C. Anatomical studies have demonstrated that the majority of terminals from trigeminal unmyelinated primary afferent axons terminate in laminae I and the underlying substantia gelatinosa of the Sp5C (Windle, 1927; Young and King, 1973; Young, 1977; Ambalavanar and Morris, 1992; Crissman et al., 1996) and rarely in the other subdivisions of the trigeminal sensory complex, which predominantly receive the terminal arbors of large and small myelinated primary trigeminal axons (Falls, 1988). The lack of direct C-fiber projection to the $\mathrm{Sp} 5 \mathrm{O}$ is also supported by autoradiographic and immunohistochemical studies that showed that putative neurotransmitters released by $\mathrm{C}$-fibers (e.g., substance $\mathrm{P}$ ) were not seen in significant amounts within the Sp5O (Rhoades et al., 1988; Nakaya et al., 1994; Sugimoto et al., 1997). This indirect activation can also be inferred from differences in latency between the $\mathrm{C}$-fiber-evoked responses recorded in the $\mathrm{Sp} 5 \mathrm{O}$ and the $\mathrm{Sp} 5 \mathrm{C}$. In similar experimental conditions, the mean latencies of the $\mathrm{C}$-fiber-evoked responses in $\mathrm{Sp} 5 \mathrm{O}$ in the present study were 12-16 msec longer than those reported in the Sp5C (59-63 msec) (Villanueva and Le Bars, 1985, 1986; Villanueva et al., 1986). A priori, three circuits might then be proposed. (1) Sp5O neurons could receive C-fiber inputs via long dendrites extending into Sp5C substantia gelatinosa. (2) Substantia gelatinosa neurons could relay $\mathrm{C}$-fiber inputs to $\mathrm{Sp} 5 \mathrm{O}$ convergent neurons. (3) Sp5O convergent neurons could be activated multisynaptically, via deeper laminae neurons of the $\mathrm{Sp} 5 \mathrm{C}$ that have been shown to be at the origin of ascending intranuclear trigeminal pathways to the Sp5O (Ikeda et al., 1984; Nasution and Shigenaga, 1987) and receive C-fiber inputs either directly via their dorsally projecting dendrites, which extend into the substantia gelatinosa (Melzack and Wall, 1965), or indirectly via substantia gelatinosa neurons (Ritz and Greenspan, 1985; Light and Kavookjian, 1988; Steedman, 1989). Thus, Sp5O neurons most likely receive their $\mathrm{C}$-inputs indirectly via the $\mathrm{Sp5C}$, and morphine blocks, either presynaptically or postsynaptically, the $\mathrm{C}$-inputs that relay through the $\mathrm{Sp} 5 \mathrm{C}$.

Interestingly, the deep laminae (V-VI) of the spinal dorsal horn and of the $\mathrm{Sp5C}$, as well as the $\mathrm{Sp5O}$, exhibit similar properties. They contain many convergent neurons that are indirectly activated by $\mathrm{C}$-fibers. Opioid receptors as well as many putative neurotransmitters released by $\mathrm{C}$-fibers (e.g., substance $\mathrm{P}$ ) are not seen in significant amounts within these regions. Finally, morphine injection near these convergent neurons had no effect, but injection into the substantia gelatinosa induced inhibition of the neuronal responses to noxious stimuli (Duggan et al., 1977) (this study). Thus, these data lead us to hypothesize that Sp5O fulfills some of the functions of the deep laminae of Sp5C and the spinal dorsal horn and could therefore be used to study the modulatory function of the substantia gelatinosa and more generally the processing of nociceptive information in the trigeminal sensory complex. Indeed, the $\mathrm{Sp} 5 \mathrm{O}$ is $3 \mathrm{~mm}$ from the substantia gelatinosa of the Sp5C. This allows various pharmacological (e.g., microinjection of excitatory amino acids, neurokinins) or electrophysiological manipulations (e.g., electrical stimulation) in the $\mathrm{Sp} 5 \mathrm{C}$ without having a direct effect on $\mathrm{Sp5O}$ convergent neurons.

In conclusion, the present study clearly shows that morphine microinjected into the $\mathrm{Sp5O}$ was inefficient in affecting the $\mathrm{C}$-fiber-evoked response of the $\mathrm{Sp5O}$ convergent neurons, whereas when it was microinjected into the $\mathrm{Sp} 5 \mathrm{C}$ it produced a strong and naloxone-reversible depression. The most effective injection sites within the Sp5C were located near the substantia gelatinosa. These results suggest that morphine exerts its antinociceptive effect on $\mathrm{Sp5O}$ convergent neurons by blocking the $\mathrm{C}$-fiber inputs that relay in the substantia gelatinosa of the Sp5C. Moreover, the pathway by which $\mathrm{Sp5O}$ convergent neurons are activated by $\mathrm{C}$-fibers in the $\mathrm{Sp} 5 \mathrm{C}$ are still not defined. Further studies are required to clarify this point. 


\section{REFERENCES}

Ambalavanar R, Morris R (1992) The distribution of binding by isolectin I-B4 from Griffonia simplicifolia in the trigeminal ganglion and brainstem trigeminal nuclei in the rat. Neuroscience 47:421-429.

Andersen RK, Lund JP, Puil E (1977) The effects of iontophoretic applications of morphine and putative neurotransmitters on neurons of the trigeminal nuclei oralis and caudalis. In: Pain in the trigeminal region (Anderson DJ, Matthews B, eds), pp 271-284. Amsterdam: Elsevier.

Arvidsson U, Riedl M, Chakrabarti S, Lee J-H, Nakano AH, Dado RJ, Loh HH, Law P-Y, Wessendorf MW, Elde R (1995) Distribution and targeting of a $\mu$-opioid receptor (MOR1) in brain and spinal cord. J Neurosci 15:3328-3341.

Atweh SF, Kuhar MJ (1977) Autoradiographic localization of opiate receptors in rat brain. I.Spinal cord and lower medulla. Brain Res 124:53-67.

Besson J-M, Chaouch A (1987) Peripheral and spinal mechanisms of nociception. Physiol Rev 67:67-185.

Burgess PR, Perl ER (1973) Cutaneous mechanoreceptors and nociceptors. In: Handbook of sensory physiology, Vol 2, Somatosensory system (Iggo A, ed), pp 29-78. Berlin: Springer.

Burkey AR, Carstens E, Wenniger JJ, Tang J, Jasmin L (1996) An opioidergic cortical antinociception triggering site in the agranular cortex of the rat that contributes to morphine antinociception. J Neurosci 16:6612-6623.

Cook AJ, Woolf CJ, Wall PD, McMahon SB (1987) Dynamic receptive field plasticity in rat spinal cord dorsal horn following C-primary afferent input. Nature 325:151-152.

Crissman RS, Sodeman T, Denton AM, Warden RJ, Siciliano DA, Rhoades RW (1996) Organization of primary afferent axons in the trigeminal sensory root and tract of the rat. J Comp Neurol 364:169-183.

Dallel R, Raboisson P, Woda A, Sessle BJ (1990) Properties of nociceptive and non-nociceptive neurons in trigeminal subnucleus oralis of the rat. Brain Res 521:95-106.

Dallel R, Luccarini P, Molat JL, Woda A (1996a) Effects of systemic morphine on the activity of convergent neurons of spinal trigeminal nucleus oralis in the rat. Eur J Pharmacol 314:19-25.

Dallel R, Luccarini P, Dualé C, Molat JL, Woda A (1996b) Mechanism of action of morphine on convergent neurons of spinal trigeminal nucleus oralis in the rat. Congress on Pain, IASP Vancouver. Abstract 30, p 149.

Dickenson AH (1995) Spinal cord pharmacology of pain. Br J Anaesth 75:193-200.

Dickenson AH, Le Bars D (1987) Supraspinal morphine and descending inhibitions acting on the dorsal horn of the rat. J Physiol (Lond) $384: 81-107$

Dickenson AH, Oliveras JL, Besson J-M (1979) Role of the raphe magnus in opiate analgesia as studied by the microinjection technique in the rat. Brain Res 170:95-111.

Ding YQ, Kaneko T, Nomura S, Mizuno N (1996) Immunohistochemical localization of $\mu$-opioid receptors in the central nervous system of the rat. J Comp Neurol 367:375-402.

Dualé C, Luccarini P, Cadet R, Woda A (1996) Effects of morphine microinjections into the trigeminal sensory complex on the formalin test in the rat. Exp Neurol 142:331-339.

Duggan AW, Hall JG, Headley PM (1977) Suppression of transmission of nociceptive impulses by morphine: selective effects of morphine administered in the region of the substantia gelatinosa. Br J Pharmacol 61:65-76.

Falls WM (1988) Synaptic organization of primary axons in trigeminal nucleus oralis. J Electron Microsc Tech 10:213-227.

Finley JCW, Maderbrut JL, Petrusz P (1981) The immunocytochemical localization of enkephalin in the central nervous system of the rat. J Comp Neurol 198:541-565.

Gasser HS, Erlanger J (1927) The role played by the sizes of the constituent fibers of a nerve trunk in determining the form of its action potential wave. Am J Physiol 80:522-547.

Gebhart GF, Jones SL (1988) Effects of morphine given in the brain stem on the activity of dorsal horn nociceptive neurons. In: Pain modulation (Fields HL, Besson J-M, eds), pp 229-243. Amsterdam: Elsevier.

Grudt TJ, Williams JT (1994) $\mu$-opioid agonists inhibit spinal trigeminal substantia gelatinosa neurons in guinea pig and rat. J Neurosci 14:1646-1654
Hökfelt TA, Elde R, Johansson O, Terenius L, Stein L (1977) The distribution of enkephalin-immunoreactive cell bodies in the rat central nervous system. Neurosci Lett 5:25-31.

Holzer P (1991) Capsaicin: cellular targets, mechanisms of action, and selectivity for thin sensory neurons. Pharmacol Rev 43:143-201.

Hu JW (1990) Response properties of nociceptive and non-nociceptive neurons in the rat's trigeminal subnucleus caudalis (medullary dorsal horn) related to cutaneous and deep craniofacial afferent stimulation and modulation by diffuse noxious inhibitory controls. Pain 41:331-345.

Hu JW, Sessle BJ, Raboisson P, Dallel R, Woda A (1992) Stimulation of craniofacial muscle afferents induces prolonged facilitatory effects in trigeminal nociceptive brain-stem neurones. Pain 48:53-60.

Ikeda M, Tanami T, Matsushita M (1984) Ascending and descending internuclear connections of the trigeminal sensory nuclei in the cat. A study with the retrograde and anterograde horseradish peroxidase technique. Neuroscience 12:1243-1260.

Jacquin MF, Semba K, Egger MD, Rhoades RW (1983) Organization of HRP-labeled trigeminal mandibular primary afferent neurons in the rat. J Comp Neurol 215:397-420.

Jessell TM, Iversen LL (1977) Opiate analgesics inhibit substance P release from rat trigeminal nucleus. Nature 268:549-551.

Johnson SM, Duggan AW (1981) Evidence that the opiate receptors of the substancia gelatinosa contribute to the depression, by intravenous morphine, of the spinal transmission of impulses in unmyelinated primary afferents. Brain Res 207:223-228.

Khachaturian H, Lewis ME, Watson SJ (1983) Enkephalin systems in diencephalon and brainstem of the rat. J Comp Neurol 220:310-320.

Le Bars D, Dickenson AH, Besson J-M (1980) Microinjection of morphine within nucleus raphe magnus and dorsal horn neurone activities related to nociception in the rat. Brain Res 189:467-481.

Light AR, Kavookjian AM (1988) Morphology and ultrastructure of physiologically identified substantia gelatinosa (Lamina II) neurons with axons that terminate in deeper dorsal horn laminae (III-V) J Comp Neurol 267:172-189.

Melzack R, Wall PD (1965) Pain mechanisms: a new theory. Science 150:971-979.

Murakami S, Okamura H, Yanaihara C, Yanaihara N, Ibata Y (1987) Immunocytochemical distribution of met-enkephalin-Arg6-Gly7-Leu8 in the rat lower brainstem. J Comp Neurol 261:193-208.

Nakaya Y, Kaneko T, Shigemoto R, Nakanishi S, Mizuno N (1994) Immunohistochemical localization of substance $\mathrm{P}$ receptor in the central nervous system of the adult rat. J Comp Neurol 347:249-274.

Nasution ID, Shigenaga Y (1987) Ascending and descending internuclear projections within the trigeminal sensory nuclear complex. Brain Res 425:234-247.

Oliveras JL, Maixner W, Dubner R, Bushnell MC, Kenshalo DR (1986) The medullary dorsal horn: a target for the expression of opiate effects on the perceived intensity of noxious heat. J Neurosci 6:3086-3093.

Paxinos G, Watson C (1986) The rat brain in stereotaxic coordinates. New York: Academic.

Raboisson P, Bourdiol P, Dallel R, Clavelou P, Woda A (1991) Responses of trigeminal subnucleus oralis nociceptive neurones to subcutaneous formalin in the rat. Neurosci Lett 125:179-182.

Raboisson P, Dallel R, Clavelou P, Sessle BJ, Woda A (1995) Effects of subcutaneous formalin on the activity of trigeminal brain stem nociceptive neurones in the rat. J Neurophysiol 73:496-505.

Rhoades RW, Chiaia NL, Hess PR, Miller MW (1988) Effect of neonatal infraorbital nerve transection on substance $\mathrm{P}$ - and leucine enkephalin-like immunoreactivities in trigeminal subnucleus caudalis of the rat. J Neurosci 8:2234-2247.

Ritz LA, Greenspan JD (1985) Morphological features of lamina V neurons receiving nociceptive input in cat sacrocaudal spinal cord J Comp Neurol 238:440-452.

Rosenfeld JP, Pickrel C, Broton JG (1983) Analgesia for orofacial nociception produced by morphine microinjection into the spinal trigeminal complex. Pain 15:145-155.

Sar M, Stumpf WE, Miller RJ, Chang KJ, Cuatrecasas P (1978) Immunohistochemical localization of enkephalin in rat brain and spinal cord. J Comp Neurol 182:17-38.

Sastry BR, Goh JW (1983) Actions of morphine and met-enkephalinamide on nociceptor driven neurones in substantia gelatinosa and deeper dorsal horn. Neuropharmacology 22:119-122.

Steedman WM (1989) The influence of cutaneous inputs on the activity of neurones in the substantia gelatinosa. In: Processing of sensory 
information in the superficial dorsal horn of the spinal cord (Cervero F, Bennett GJ, Headley PM, eds), pp 145-158. New York: Plenum.

Suarez-Roca H, Maixner W (1992) Morphine produces a multiphasic effect on the release of substance P from rat trigeminal nucleus slices by activating different opioid receptor subtypes. Brain Res 579:195-203.

Sugimoto T, Fujiyoshi Y, Xiao C, He YF, Ichikawa H (1997) Central projection of calcitonin gene-related peptide (CGRP)- and substance $\mathrm{P}$ (SP)-immunoreactive trigeminal primary neurons in the rat. J Comp Neurol 378:425-442.

Sumal KK, Pickel VM, Miller RJ, Reis DJ (1982) Enkephalincontaining neurons in substantia gelatinosa of spinal trigeminal complex: ultrastructure and synaptic interaction with primary sensory afferents. Brain Res 248:223-236.

Takemura M, Sugimoto T, Shigenaga Y (1991) Difference in central projection of primary afferents innervating facial and intraoral structures in the rat. Exp Neurol 111:324-331.

Thomas DA, Oliveras JL, Iwata K, Maixner W, Dubner R (1992) Systemic morphine administration attenuates the perceived intensity of noxious heat in the monkeys. Pain 49:129-135.

Villanueva L, Le Bars D (1985) The encoding of thermal stimuli applied to the tail of the rat by lowering the excitability of trigeminal convergent neurones. Brain Res 330:245-251.

Villanueva L, Le Bars D (1986) Indirect effects of intrathecal morphine upon diffuse noxious inhibitory controls (DNICs) in the rat. Pain 26:233-243.

Villanueva L, Le Bars D (1995) The activation of bulbo-spinal controls by peripheral nociceptive inputs: diffuse noxious inhibitory controls. Biol Res 28:113-125.

Villanueva L, Peschanski M, Calvino B, Le Bars D (1986) Ascending pathways in the spinal cord involved in triggering of diffuse noxious inhibitory controls in the rat. J Neurophysiol 55:34-55.
Villanueva L, Bouhassira D, Bing Z, Le Bars D (1988) Convergence of heterotopic nociceptive information onto subnucleus reticularis dorsalis neurons in the rat medulla. J Neurophysiol 60:980-1009.

Willis Jr WD, Coggeshall RE (1991) Sensory mechanisms of the spinal cord, Ed 2. New York: Plenum.

Windle WF (1927) Experimental proof of the types of neurons that innervate the tooth pulp. J Comp Neurol 43:347-356.

Woolf CJ, Wall PD (1986) Relative effectiveness of C primary afferent fibers of different origins in evoking a prolonged facilitation of the flexor reflex in the rat. J Neurosci 6:1433-1442.

Yaksh TL, Al-Rodhan NRF, Jensen TS (1988) Sites of action of opiates in production of analgesia. Prog Brain Res 77:371-394.

Yonehara N, Shibutani T, Tsai HY, Inoki R (1986) Effects of opioids and opioid peptide on the release of substance P-like material induced by tooth pulp stimulation in the trigeminal nucleus caudalis of the rabbit. Eur J Pharmacol 129:209-216.

Yonehara N, Shibutani T, Imai Y, Inoki R (1990) Involvement of descending monoaminergic systems in the transmission of dental pain in the trigeminal nucleus caudalis of the rabbit. Brain Res 508:234-240.

Young RF (1977) Fiber spectrum of the trigeminal sensory root of frog, cat and man determined by electronmicroscopy. In: Pain in the trigeminal region (Anderson DJ, Matthews B, eds), pp 137-147. Amsterdam: Elsevier.

Young RF, King RB (1973) Fiber spectrum of the trigeminal sensory root of the baboon determined by electron microscopy. J Neurosurg 38:65-72.

Zhang K-M, Wang XM, Mokha SS (1996) Opioids modulate $N$-methylD-aspartic acid (NMDA)-evoked responses of neurons in the superficial and deeper dorsal horn of the medulla (trigeminal nucleus caudalis). Brain Res 719:229-233. 